\title{
VARIAÇÃO FENOTÍPICA EM PLANTAS DE DUAS FAMÍLIAS DE MEIOS-IRMÃOS DE GOIABEIRA-SERRANA (Acca sellowiana Berg.) EM UM POMAR COMERCIAL EM SÃO JOAQUIM-SC ${ }^{1}$
}

\author{
JULIANA DEGENHARDT ${ }^{2}$, JEAN-PIERRE DUCROQUET ${ }^{3}$, MIGUEL PEDRO GUERRA $^{4}$, RUBENS ONOFRE NODARI ${ }^{4}$
}

\begin{abstract}
RESUMO - A goiabeira-serrana (Acca sellowiana Berg.) é uma mirtácea nativa do planalto meridional brasileiro, com dispersão secundária no Uruguai, e produz um fruto de sabor único. Plantas de um pomar comercial composto por duas famílias de meios-irmãos (FMI1 e FMI2) foram avaliadas, com o objetivo principal de analisar a variabilidade fenotípica de várias características. As médias ( \pm desvio-padrão) obtidas para as

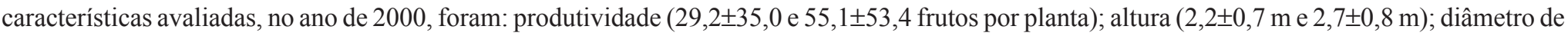
copa $(1,9 \pm 0,7 \mathrm{~m}$ e $2,1 \pm 0,7 \mathrm{~m})$; número de ramificações a $20 \mathrm{~cm}$ do solo $(2,4 \pm 1,5$ e $1,6 \pm 1,2)$ e distância entre o estigma e as anteras na flor $(0,5 \pm 0,2 \mathrm{~cm}$ e $0,2 \pm 0,2 \mathrm{~cm}$ ), para as plantas da FMI1 e da FMI2, respectivamente. As avaliações revelaram diferenças estatisticamente significativas entre as duas famílias para as características avaliadas, com exceção de diâmetro de copa. As correlações entre características vegetativas não foram estatisticamente significativas, com exceção da correlação entre a altura e a distância entre estigma e anteras $(\mathrm{r}=-0,53)$ para a FMI1, no ano de 2000 . As regressões não foram significativas, com exceção da regressão entre altura e produtividade na FMI1, em 1998, e entre a produtividade e a distância entre estigma e anteras na FMI2, em 2000. Porém, todas apresentaram coeficientes de determinação inferiores a 0,15.
\end{abstract}

Termos para indexação: variabilidade fenotípica, Myrtaceae, feijoa, fruteiras nativas.

\section{PLANT PHENOTYPIC VARIATION OF TWO HALF SIB FAMILIES OF FEIJOA (Acca sellowiana Berg.) FROM AN ORCHARD IN SÃO JOAQUIM, SC}

ABSTRACT - Feijoa (Acca sellowiana Berg.) is a native Myrtaceae of the Brazilian Southern plateau with secondary dispersion in Uruguay and its fruit has a unique flavor. Plants of a commercial orchard of this species originated by two half-sib families (FMI1 and FMI2) were evaluated, with the objective to characterize the phenotypic variation of several traits. The means ( \pm standard deviation) of the evaluated traits, obtained in 2000 were: productivity ( $29.2 \pm 35.0$ and $55.1 \pm 53.4$ fruits per plant); height $(2.2 \pm 0.7 \mathrm{~m}$ and $2.7 \pm 0.8 \mathrm{~m})$, canopy diameter $(1.9 \pm 0.7 \mathrm{~m}$, and $2.1 \pm 0.7 \mathrm{~m})$, number of ramifications at $20 \mathrm{~cm}$ of the soil $(2.4 \pm 1.5$ and $1.6 \pm 1.2)$ and distance between the stigma and the anthers in the flower $(0.5 \pm 0.2 \mathrm{~cm}$ and $0.2 \pm 0.2 \mathrm{~cm})$ for FMI1 and FMI2, respectively. The evaluations revealed significant statistical differences between the two families for plants traits evaluated, except for canopy diameter. The correlations among vegetative traits were not significant, except for height $\mathrm{x}$ distance between stigma and anthers $(\mathrm{r}=-0.53)$ for FMI1 in 2000. The regressions were not significant, except the regressions between height and productivity for FMI1 in 1998 and between productivity and distance between stigma and anthers in FMI2, in 2000, all with $\mathrm{R}^{2}<0.15$.

Index terms: phenotypic variability, Myrtaceae, feijoa, native fruits.

\section{INTRODUÇÃO}

A goiabeira-serrana é uma fruteira nativa do planalto meridional brasileiro com dispersão secundária no Uruguai. A planta atinge em média quatro metros de altura, e o início de produção se dá a partir do quarto ano (Mattos, 1986). Apesar do potencial comercial de seus frutos e de ser comercializada na Europa e nos Estados Unidos, a espécie é ainda pouco conhecida no País (Ducroquet et al., 2000), embora tenha sido bem aceita nos ensaios realizados nos anos de 2000 e 2001 em Blumenau e Florianópolis, respectivamente, os quais demonstraram que aproximadamente $90 \%$ dos entrevistados consideram ótimo ou bom o sabor e o aroma dos frutos (Barni et al., 2004).

Para o cultivo comercial ser viável, é importante que as variedades selecionadas reúnam características superiores às plantas em estado natural, em termos de produtividade, estabilidade na produção e qualidade de frutos. Para que tais variedades sejam constituídas, é necessário que haja variabilidade suficiente na espécie, capaz de prover indivíduos que possam ser utilizados em programas de melhoramento (Allard, 1999). Portanto, o estudo dos componentes da variabilidade fenotípica da espécie é importante principalmente para espécies nativas ainda pouco estudadas, cuja magnitude da variabilidade é desconhecida.

Várias espécies, apesar de não terem ainda cultivo comercial expressivo, já estão sendo caracterizadas quanto à sua variabilidade genética para fins não apenas de melhoramento, mas também de preservação. Tais estudos vêm demonstrando que ainda existe grande variabilidade fenotípica e genotípica para essas espécies, com alguns genótipos bastante promissores, como é o caso da jabuticabeira (Pereira et al., 2000), também da família Myrtaceae.

A variabilidade genotípica da goiabeira-serrana vem sendo caracterizada a partir dos acessos do Banco Ativo de Germoplasma BAG, da espécie, localizado em São Joaquim-SC. Esses estudos são baseados em locos alozímicos, de microssatélites e em fragmentos aleatórios amplificados de DNA (RAPD), os quais vêm demonstrando variabilidade expressiva entre aquelas plantas (Nodari et al., 1997; Welter et al., 1999; Santos et al., 2002).

Contudo, o estudo da variabilidade fenotípica de populações dessa espécie é ainda incipiente, embora cultivares já tenham sido desenvolvidas na Nova Zelândia e nos Estados Unidos, entre outros. No entanto, estas cultivares possuem base genética restrita, uma vez que são todas provenientes de material oriundo do Uruguai (Ducroquet et al., 2000). Avaliando características de frutos, como peso, diâmetro e teor de sólidos solúveis totais em duas famílias de meios-irmãos, Degenhardt et al. (2003) detectaram diferenças estatísticas significativas entre as médias de famílias em, pelo menos, dois dos três anos avaliados.

As correlações simples e a análise de regressão são utilizadas com freqüência em plantas de ciclo longo, principalmente nas nativas, nas quais, muitas vezes, os experimentos não se encontram delineados. Seu conhecimento é útil, principalmente quando há dificuldade na seleção de um caráter, em razão de sua baixa herdabilidade, ou se este for de difícil mensuração ou identificação (Falconer, 1987). Em alguns casos, estas análises são consideradas suficientes para esclarecer relações entre caracteres de importância econômica para estas culturas.

Este estudo teve por objetivos avaliar a variação fenotípica de várias características entre duas famílias de meios-irmãos e estimar as

\footnotetext{
(Trabalho 052/2005). Recebido: 24/03/2005. Aceito para publicação: 04/11/2005.

${ }^{2}$ Mestre em Recursos Genéticos Vegetais, CCA/UFSC. Florianópolis, SC. E-mail: Juliana.Degenhardt@gmx.de

${ }^{3}$ Doutor em Biologia e Fisiologia Vegetal, Pesquisador da EPAGRI, São Joaquim, SC.

${ }^{4}$ Professor Doutor do CPG - Recursos Genéticos Vegetais, CCA/UFSC; Depto de Fitotecnia, CP-476, Florianópolis, SC. CEP 88040-900. E-mail: nodari@cca.ufsc.br
} 
correlações e regressões entre caracteres avaliados na goiabeira-serrana.

\section{MATERIAL E MÉTODOS}

O pomar comercial de goiabeira-serrana avaliado localiza-se no Município de São Joaquim-SC, a uma altitude de aproximadamente $1.350 \mathrm{~m}$ e foi implantado em 1985 . As 889 plantas foram obtidas a partir de sementes, sendo as filas 1 a 17 progênies de uma planta-matriz (FMI1) e as filas 18 a 26 progênies de outra planta-matriz (FMI2), constituindose o pomar de duas famílias de meios-irmãos. As plantas-matrizes foram escolhidas no campo pelo proprietário do pomar, por apresentarem características de fruto e arquitetura de plantas consideradas desejáveis pelo mesmo.

Características avaliadas - A distância entre estigma e anteras foi avaliada em 10 flores de 91 plantas escolhidas aleatoriamente entre as duas famílias, sendo que as flores foram comprimidas de forma que os estames ficassem junto ao pistilo. As flores avaliadas apresentavamse no estágio fenológico F2 (Ducroquet \& Hickel, 1991). As plantas foram classificadas de acordo com a distância entre estigma e anteras, conforme Degenhardt et al. (2001): Classe 1 - distância variando entre 0 e $0,4 \mathrm{~cm}$; Classe 2 - distância variando entre 0,5 e $0,9 \mathrm{~cm}$; Classe 3 distância variando entre 1,0 e 1,4 cm. As plantas foram classificadas em seis classes de acordo com o número de frutos, contados nos anos de 1998, 1999 e 2000. Classe 0 - de 0 a 10 (média de 5) frutos; Classe 1 - de 11 a 40 (média de 25) frutos; Classe 2 - de 41 a 80 (média de 60) frutos; Classe 3 - de 81 a 120 (média de 100) frutos; Classe 4-de 121 a 160 (média de 140) frutos; Classe 5 - mais de 161 (média de 180) frutos. A medida na altura de plantas, tomada nos anos de 1998 e 2000, consistiu na distância da superfície do solo até a folha mais alta. O diâmetro de copa foi tomado na parte mais larga da copa, em 2000. O número de ramificações foi medido a $20 \mathrm{~cm}$ do solo, no ano de 2000 .

Foi realizada a análise descritiva (Steel e Torrie, 1980) de plantas do pomar para os três anos de avaliação (média, desvio-padrão, valores máximo e mínimo). Com base nestas estatísticas, as duas famílias foram comparadas entre si para os três anos, utilizando-se dos testes de chiquadrado $\left(\chi^{2}\right)$ e de t-student. Posteriormente, foram estimados os coeficientes de correlação de Pearson e os coeficientes de regressão entre características vegetativas.

Foi ainda testada a influência ambiental sobre a produtividade, devida preponderantemente ao fator solo, a partir do teste de separação de médias SNK. Para tanto, considerou-se a média da característica de cada planta nos três anos de avaliação e, a seguir, obtiveram-se as médias de cada fila. A partir da análise de variância, foram estimados os componentes da variação entre e dentro de filas para o cálculo da herdabilidade no sentido amplo (Falconer, 1987) para a produtividade (número de frutos por planta).

\section{RESULTADOS E DISCUSSÃO}

Com o objetivo de avaliar as características de plantas que possam tornar-se importantes no processo de seleção, a variabilidade fenotípica foi estudada com base em diferentes análises estatísticas. As médias de distância entre estigma e anteras das duas famílias foram diferentes estatisticamente, com base nos testes de contingência $\left(\chi^{2}\right)$ e no teste t-student. Enquanto na FMI1 $57 \%$ das plantas apresentaram flores com distância entre 0,4 e $0,9 \mathrm{~cm}, 95 \%$ das plantas da FMI2 apresentaram distância inferior a $0,4 \mathrm{~cm}$ (Tabela 1). Como valores acima de 1 para esta distância foram observados em outras plantas (Degenhardt et al., 2001), a variação de 0,1 a 0,9 é a primeira evidência de que esta característica deve ter um forte componente genético.

TABELA 1 - Médias e valores mínimos e máximos (entre parênteses) para as características de plantas: distância entre estigma e estames nas flores, diâmetro de copa e número de ramos a $20 \mathrm{~cm}$ do solo para todas as plantas do pomar e para as Famílias 1 e 2 (FMI1 e FMI2), avaliadas no ano de 2000, São Joaquim-SC.

\begin{tabular}{lccc}
\hline Família & $\begin{array}{c}\text { Distância } \\
\text { estigma/estames }(\mathrm{cm})\end{array}$ & $\begin{array}{c}\text { Diâmetro de } \\
\text { copa }(\mathrm{m})\end{array}$ & $\begin{array}{c}\text { Número de } \\
\text { ramos }\end{array}$ \\
\hline FMI1 & $0,5 \mathrm{a}(0,2-1,0)$ & $1,9 \mathrm{a}(0,7-3,2)$ & $2,4 \mathrm{a}(1,0-10)$ \\
FMI2 & $0,2 \mathrm{a}(0,1-0,6)$ & $2,1 \mathrm{a}(0,7-4,0)$ & $1,6 \mathrm{a}(1,0-7,0)$ \\
\hline Todas & $0,4(0,1-1,0)$ & $2,0(0,7-4,0)$ & $2,1(1,0-10)$ \\
\hline
\end{tabular}

Médias de características no mesmo ano e nas duas famílias, seguidas da mesma letra, não diferem estatisticamente, pelo t-teste ( $5 \%)$.

Apesar dessa diferença, os coeficientes de correlação entre esta característica e a produtividade não foram estatisticamente significativos, não tendo ficado comprovada a influência dessa característica sobre o número de frutos produzidos. Tampouco a análise de regressão entre essas características revelou a existência de dependência entre ambas. Entretanto, a relação entre essa característica e a polinização já foi demonstrada em estudo anterior, no qual flores com menores distâncias entre estigma e anteras facilitaram a polinização por insetos, por possibilitar que estes, ao caminharem sobre os estames para coletar pólen, tocassem o estigma (Degenhardt et al., 2001).

$\mathrm{O}$ fato de terem ocorrido apenas duas classes para esta característica, mostrou que as plantas do pomar apresentam menor variabilidade do que a encontrada no BAG, em São Joaquim, onde, dentre 15 acessos estudados, foi possível a distinção das três classes (Degenhardt et al., 2001). Esse fato pode ser explicado pelo grau de parentesco entre as plantas do pomar e demonstra a maior variabilidade existente no BAG

A produção de frutos por planta variou de 0 a mais de 180 , sugerindo que existe a possibilidade para a seleção com o aumento do número de frutos (Figura 1). Além disso, o número médio de frutos por planta foi superior na FMI2, comparativamente à FMI1, sendo essa diferença estatisticamente significativa, com base no teste de contingência $\left(\chi^{2}\right)$ e no teste t-student (Tabela 2). Apenas $1,2 \%$ das plantas da FMI1 produziu mais de 100 frutos em dois anos de avaliação (classes 3; 4 e 5). Esse número foi de 21,3\% das plantas para as da FMI2. Variação de produção observada entre anos na mesma planta sugere que a alternância de produção possa ocorrer para a espécie.

Apesar do aumento no número de frutos produzidos ao longo do tempo, muitas plantas produziram menos de 40 frutos nos três anos avaliados, em ambas as famílias. Como as plantas já estão com mais de 15 anos de idade, é provável que esta baixa produtividade seja devida

TABELA 2 - Médias, desvios-padrão e valores mínimos e máximos (entre parênteses) para as características de plantas: produtividade (número de frutos por planta) e altura, para todas as plantas do pomar e para as Famílias 1 e 2 (FMI1 e FMI2), avaliadas nos anos de 1998, 1999 e 2000. São Joaquim-SC.

\begin{tabular}{lcccc}
\hline Característica & Família & $\mathbf{1 9 9 8}$ & $\mathbf{1 9 9 9}$ & $\mathbf{2 0 0 0}$ \\
\hline Produtividade & FMI1 & $13,6 \pm 18,2(5-140) \mathrm{a}$ & $28,6 \pm 27,5(5-140) \mathrm{a}$ & $29,2 \pm 35,0(5-180) \mathrm{a}$ \\
(n' $\mathbf{n}^{\mathbf{2}}$ de frutos & FMI2 & $36,2 \pm 40,4(5-180) \mathrm{b}$ & $66,3 \pm 56,6(5-180) \mathrm{b}$ & $55,1 \pm 53,4(5-180) \mathrm{b}$ \\
\cline { 2 - 5 } por planta) & Todas & $21,9 \pm 30,5(5-180)$ & $42,0 \pm 44,1(5-180)$ & $38,5 \pm 44,3(5-180)$ \\
\hline Altura (m) & FMI1 & $1,8 \pm 0,7(0,1-3,5) \mathrm{a}$ & $2,2 \pm 0,7(0,2-3,5) \mathrm{a}$ \\
& FMI2 & $2,3 \pm 0,9(0,2-5,5) \mathrm{b}$ & $2,7 \pm 0,8(0,2-5,5) \mathrm{b}$ \\
\cline { 2 - 5 } & Todas & $2,0 \pm 0,8(0,1-5,5)$ & $2,4 \pm 0,8(5-180)$ \\
\hline
\end{tabular}

Médias de características no mesmo ano e nas duas famílias, seguidas da mesma letra maiúscula, não diferem estatisticamente, pelo t-teste (5\%). 

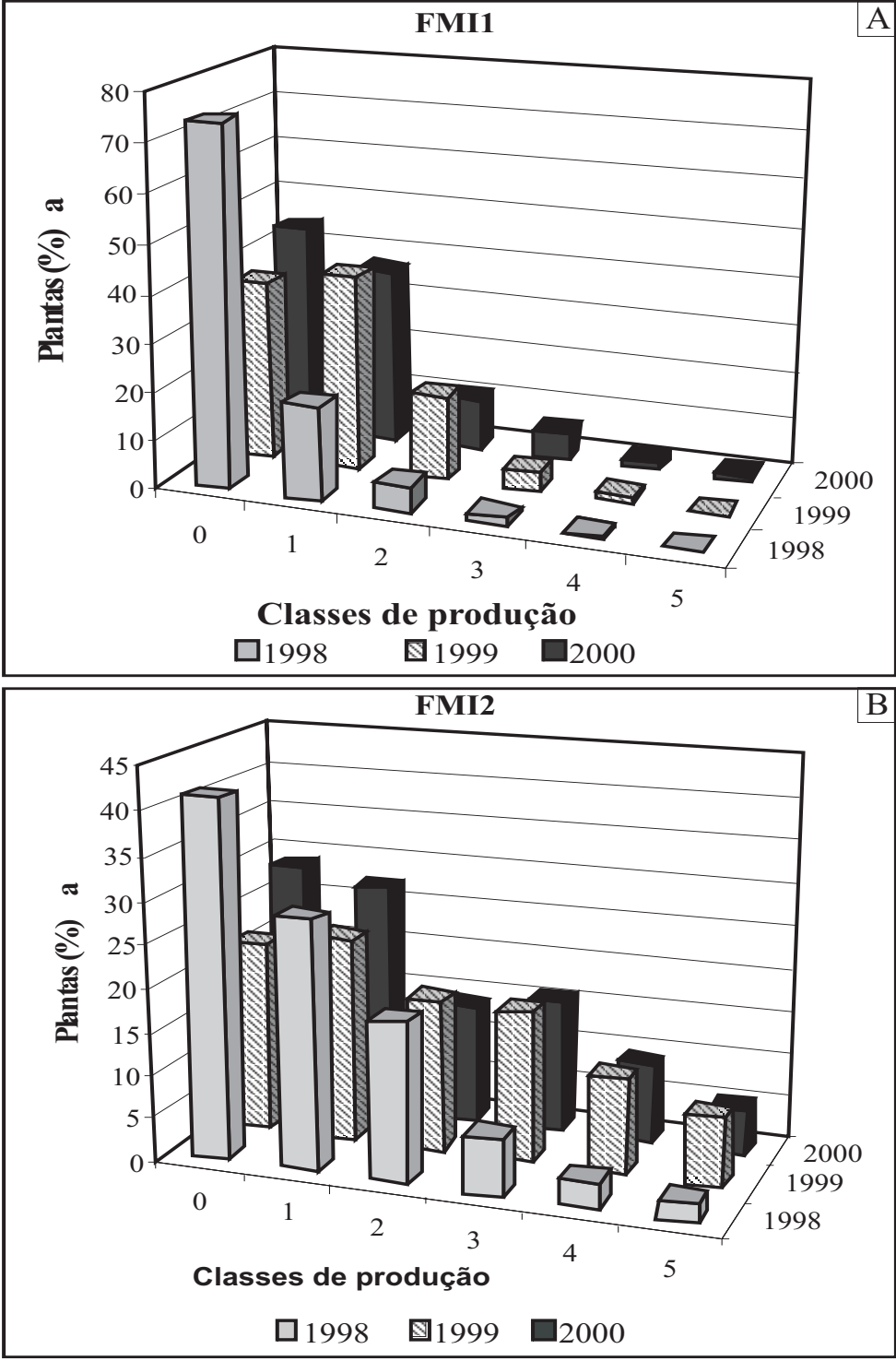

FIGURA 1 - Percentagem de plantas em seis classes de produção de frutos avaliadas nos anos de 1998, 1999 e 2000. São Joaquim-SC. Classes de produção: 0 - média de 5 frutos; 1 - média de 25 frutos; 2 - média de 60 frutos; 3 - média de 100 frutos; 4 - média de 140 frutos, e 5 -média de 180 frutos. A - família de meios-irmãos 1, B - família de meiosirmãos 2 .

ao seu genótipo ou à interação genótipo $\mathrm{x}$ ambiente, que pode estar agindo de maneira diferenciada para as duas famílias (Figura 1).

A produtividade do pomar, no ano de 2000 , considerando-se uma produção média de 38 frutos/planta e o peso médio de frutos de 81 gramas (Degenhardt et al., 2003), foi de 1,84 t/ha. Se considerarmos apenas a produção de polpa, a produtividade cairia para $445 \mathrm{~kg} / \mathrm{ha}$, uma vez que o rendimento médio de frutos nesse ano foi de $24 \%$. Se o processo de seleção permitisse a implantação de um pomar com o mesmo espaçamento do pomar avaliado $(2 \times 6 \mathrm{~m})$, com médias baseadas nas médias das melhores plantas avaliadas, poder-se-ia chegar a um rendimento de $12,9 \mathrm{t} / \mathrm{ha}$, sete vezes superior à média do pomar em 2000 , considerando-se uma produtividade média de 180 frutos (média da classe mais produtiva) e uma média de peso de fruto de $120 \mathrm{~g}$ (o valor máximo para as plantas foi de $160 \mathrm{~g}$ ). Se o rendimento de polpa fosse considerado $40 \%$ (o valor máximo foi de $47 \%$ ), o rendimento de polpa/ha saltaria para $5,1 \mathrm{t} / \mathrm{ha}$. Deve-se destacar o fato de que esses cálculos foram baseados apenas nas plantas avaliadas. Esses valores demonstram a importância e a oportunidade do melhoramento para essa espécie.

Considerando-se o rendimento médio (24,5 t/ha) dos pomares de macieira no Estado de Santa Catarina, a cultura mais importante na região, a produtividade da goiabeira-serrana ainda seria baixa. Contudo, a variabilidade existente na espécie suporta um programa de melhoramento que, se intensivo, pode vir a aumentar esses valores ainda mais, tornando-a competitiva, além de mais uma alternativa para o pequeno produtor. $\mathrm{O}$ estudo de produtividade para cupuaçuzeiro, outra espécie nativa em processo de domesticação, foi em torno de 1,6 t de polpa/ha, não diferindo muito do valor obtido para a feijoa no pomar atual. A produtividade média no estudo foi de 13,9 frutos por planta, com peso médio variando entre 887 e $1.137 \mathrm{~g}$, com rendimento de polpa médio de 35\% (Souza et al., 1998).

As médias de produtividade por fila foram calculadas para testar a influência do solo, com base na análise de variância e no teste de separação de médias SNK (Tabela 3). Para tanto, foram consideradas todas as plantas de cada fila (em média 36 plantas). Verificou-se que o fator solo não parece estar afetando de maneira diferencial o rendimento médio das plantas. É possível então inferir que a superioridade da FMI2 seja em grande parte de ordem genética. A herdabilidade no sentido amplo, obtida para esta característica, calculada com base na variância entre e dentro de filas, foi igual a 0,73 , demonstrando a possibilidade de ganhos expressivos na seleção desse caráter, pelo menos nos primeiros ciclos.

TABELA 3 - Produtividade média de plantas das filas, baseadas na média da produtividade (número de frutos por planta) avaliada nos anos de 1998, 1999 e 2000.

\begin{tabular}{cc|cc}
\hline \multicolumn{2}{c}{ FMI1 } & \multicolumn{2}{c}{ FMI2 } \\
\hline Fila & Média & Fila & Média \\
\hline 26 & $55,40 \mathrm{ab}$ & 17 & $36,30 \mathrm{ab}$ \\
25 & $50,97 \mathrm{ab}$ & 16 & $22,53 \mathrm{~b}$ \\
24 & $71,97 \mathrm{a}$ & 15 & $17,13 \mathrm{~b}$ \\
23 & $45,43 \mathrm{ab}$ & 14 & $13,07 \mathrm{~b}$ \\
22 & $54,93 \mathrm{ab}$ & 13 & $12,70 \mathrm{~b}$ \\
21 & $51,03 \mathrm{ab}$ & 12 & $20,03 \mathrm{~b}$ \\
20 & $52,53 \mathrm{ab}$ & 11 & $18,77 \mathrm{~b}$ \\
19 & $44,97 \mathrm{ab}$ & 10 & $27,80 \mathrm{~b}$ \\
18 & $42,13 \mathrm{ab}$ & 9 & $18,63 \mathrm{~b}$ \\
& & 8 & $29,67 \mathrm{~b}$ \\
& & 7 & $37,30 \mathrm{ab}$ \\
& & 6 & $15,50 \mathrm{~b}$ \\
& & 5 & $33,73 \mathrm{ab}$ \\
& & 4 & $19,00 \mathrm{~b}$ \\
& & 3 & $27,87 \mathrm{~b}$ \\
& & 2 & $25,70 \mathrm{~b}$ \\
\hline Média & $\mathbf{5 2 , 1 5}$ & Média & $\mathbf{2 4 , 3 8}$ \\
\hline
\end{tabular}

Valores seguidos da mesma letra não diferem entre si, pelo teste SNK, nível de $5 \%$ de probabilidade. $(\mathrm{n}=36$ plantas por fila)

A produtividade das plantas avaliadas não pode ser considerada definitiva. Em análise anterior, onde foi avaliado o coeficiente de repetibilidade para essa característica com base na avaliação de três anos, demonstrou-se a variação para essa característica para uma mesma planta, nos três anos de avaliação. Os valores observados nesse estudo mostraram a necessidade de avaliação em 5 anos para se obter uma estimativa com coeficiente de determinação igual a $80 \%$. O fato de essa característica ter sido variável entre os anos, levou à sugestão da existência de alternância de produção para a espécie (Degenhardt et al., 2002).

A diferença na média da altura entre as duas famílias deve ser, em parte, atribuída ao genótipo destas e foi estatisticamente significativa, com base nos testes de contingência $\left(\chi^{2}\right)$ e t-student (Tabela 2, Figura 2). A ausência de correlação entre esta característica e a produtividade possibilita a seleção de plantas de menor porte com maior produção de frutos.

A diferença no diâmetro de copa entre as duas famílias não foi muito acentuada (Tabela 1) e, apesar de estatisticamente significativa com base no teste de contingência $\left(\chi^{2}\right)$, não foi significativa com base no t-teste (Figura 3 ). 


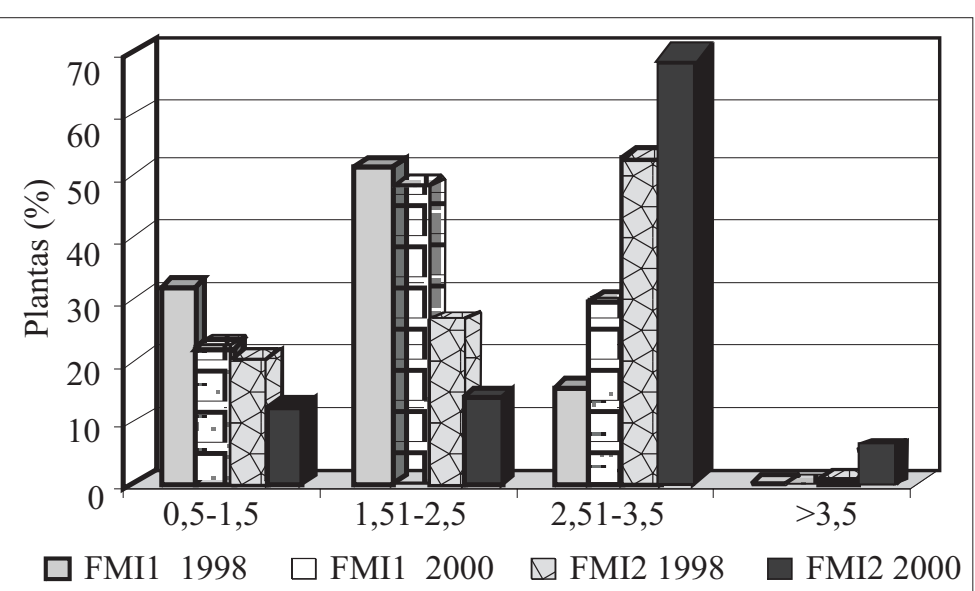

FIGURA 2 - Percentagem de plantas por classes de altura, avaliada nos anos de 1998 e 2000. São Joaquim-SC.

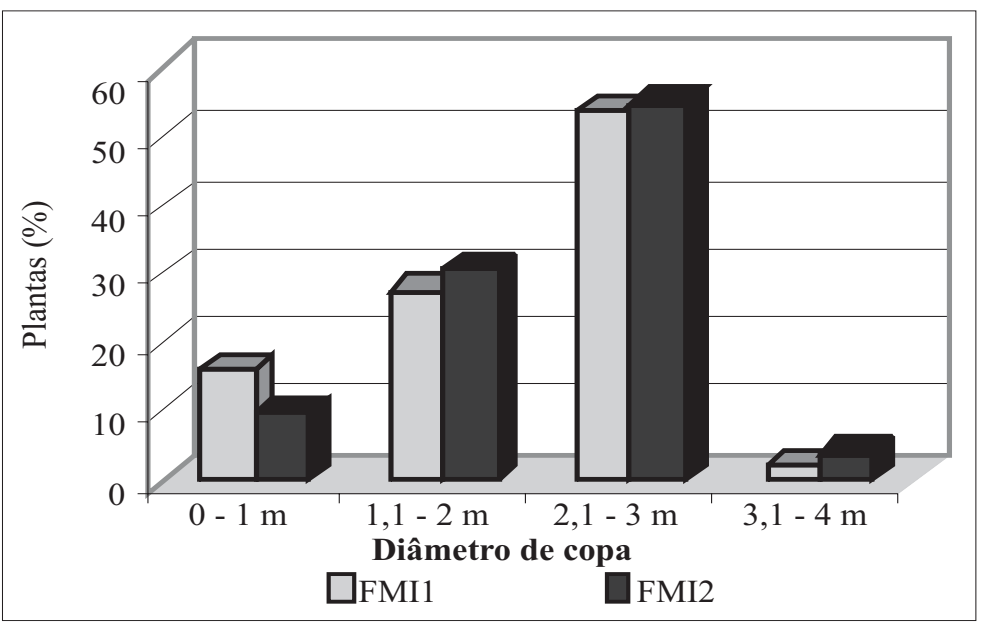

FIGURA 3 - Percentagem de plantas por classes de diâmetro de copa, avaliado em 2000. São Joaquim-SC.

As duas famílias também diferiram estatisticamente (com base no teste do $\chi^{2}$ e no t-student) para número de ramos a $20 \mathrm{~cm}$ do solo, tendo as plantas da FMI1 apresentado, em média, maior número (Tabela 1). A quantidade de plantas sem bifurcação foi de $1 / 3$ das plantas da FMI1 e 2/3 das da FMI2. Enquanto mais de 2/3 das plantas da FMI1 apresentaram três ou mais ramos a $20 \mathrm{~cm}$, esse número foi de apenas 13,2\% das plantas da FMI2. Verificou-se também que muitas plantas da FMI1 já se apresentavam ramificadas desde a base do solo, característica pouco comum na FMI2. Esta tendência de ramificação precoce também é vista em goiabeira (Psidium guajava) e jabuticabeira (Myrciaria cauliflora), ambas da família Myrtaceae, cujo caule, de diâmetro variável, também pode ser ramificado desde a base, devido ao desaparecimento da gema apical (Manica et al., 2000).

As correlações calculadas entre as características de plantas não foram significativas, com exceção da correlação negativa, observada entre distância entre estigma e anteras e altura de plantas da FMI1, no ano de $2000(\mathrm{r}=-0,53)$. Essa correlação, porém, não foi observada na mesma família em 1998. As equações de regressão estatisticamente significativas obtidas entre as características vegetativas foram: 1) $\mathrm{ALT}=229,34+0,39 \mathrm{PRD}\left(\mathrm{R}^{2}=0,06\right)$ na FMI1, em 1998; 2$) \mathrm{ALT}=335,6$ $0,20 \mathrm{PRD}\left(\mathrm{R}^{2}=0,12\right)$ e 3$) \mathrm{PRD}=143,1-117,5 \mathrm{DEE}\left(\mathrm{R}^{2}=0,10\right)$ naFMI2, em 2000. Nestes três casos, os coeficientes de determinação foram baixos, demonstrando a ausência de associação.

Os valores de correlação e regressão entre duas mesmas variáveis, nos três anos de avaliação, não foram consistentes, indicando que tanto os anos quanto as famílias e a interação entre ambos afetam tais valores. A ausência de correlação entre características morfológicas de plantas não parece ser muito comum, principalmente quando são relacionadas características como altura e diâmetro de copa. Para o umbuzeiro, encontrou-se correlação de 0,76 entre estas características, de 0,23 entre altura e número de frutos produzidos e 0,15 entre número de frutos produzidos e diâmetro de copa (Santos \& Nascimento, 1998) e de 0,29 entre altura de planta e diâmetro de caule na aceroleira (Gomes et al., 2000).

O avanço nos programas de melhoramento é dependente e influencia nos valores de correlação entre as características, como é o caso da correlação negativa entre altura e conformação de copa em aceroleira, em estudo realizado sobre progênies de plantas selecionadas. Essa correlação é devida à seleção efetuada no sentido de manter um ideótipo de planta com copa de guarda-chuva, o que mantém as plantas reduzidas, facilitando a colheita (Paiva et al., 1999). Porém, a correlação entre essas características em estudo com plantas não selecionadas foi de 0,72 (Paiva et al., 1999). Estudos em cultivos de pepino mostraram diferenças causadas pela seleção nas correlações entre características, demonstrando que houve mudanças em suas magnitudes após a seleção. Muitas das correlações, tanto fracas quanto fortes, permaneceram constantes ao longo dos ciclos de seleção, porém algumas correlações fracas tornaram-se negativas ao final de 10 ciclos de seleção e outras ainda, consideradas fortes nos ciclos inicias, tornaram-se fracas ao longo desse período. Apesar disso, estas mudanças nas magnitudes não foram acompanhadas em muitos casos, por mudanças nas médias das características correlacionadas. Os autores verificaram, ainda, diferenças entre as magnitudes das correlações entre as safras, no mesmo ano (Cramer \& Wehner, 1998).

Os resultados obtidos revelam variação entre as duas famílias quanto à arquitetura de plantas. Enquanto a FMI1 apresenta plantas mais baixas, com menor diâmetro de copa, mais ramificadas e menos produtivas, a FMI2 apresenta plantas mais altas, com maior diâmetro de copa, menos ramificadas a $20 \mathrm{~cm}$ do solo e mais produtivas. Para a implantação de pomares comerciais, para que seja possível uma maior densidade de plantas e maior facilidade nos tratos culturais visando a uma maior produtividade, é importante que se selecionem plantas de porte mais baixo, mas com alta produtividade, o que é possível no pomar, uma vez que não houve correlação entre essas características. A partir dos resultados obtidos, observou-se a possibilidade de selecionar plantas com menor altura e maior produtividade, revelando assim a aplicabilidade das informações obtidas neste trabalho. A seleção não poderá ser baseada apenas nessas duas características, mas estas plantas podem ser usadas em cruzamentos, com plantas que apresentem características complementares. Quanto à quantidade de ramos, deve-se atentar para os fatores mais importantes de manejo e produção, porém a prática da poda deve contornar o que pode vir a ser um problema quando as plantas são ramificadas desde a base, dificultando os tratos culturais.

A Acca sellowiana ainda encontra-se em estágio de domesticação e, por isso, os parâmetros a serem levados em consideração no melhoramento genético da espécie ainda não foram estabelecidos. Entretanto, a avaliação de frutos (Degenhardt et al., 2003) e das plantas do pomar em estudo sugere como características prioritárias a produção de plantas, bem como a uniformização de seus frutos para a viabilização de pomares comerciais. A arquitetura da planta também é um fator que deve ser levado em consideração, pois, embora a condução da planta seja possível a partir de práticas culturais, certas características podem vir a diminuir o tempo e a mão-de-obra necessários para tais práticas.

A qualidade do fruto também deve ser levada em consideração, porém estudos mais detalhados com relação às suas qualidades nutritivas ainda não foram realizados. Além das características citadas, genótipos que apresentem resistência ou tolerância ao fungo Colletotrichum gloeosporioides, causador da antracnose, também devem começar a ser selecionados, uma vez que a doença já apresenta um problema em pomares no Sul do Brasil.

Cruzamentos dirigidos já foram efetuados visando tanto ao estudo da herança de diversas características como à obtenção de populações segregantes para a seleção de tipos superiores. Assim, tipos superiores poderão ser selecionados e disseminados para cultivo comercial. 


\section{CONCLUSÕES}

1. Houve variação fenotípica expressiva entre famílias para todas as características morfológicas avaliadas.

2. As correlações entre os caracteres morfológicos avaliados não foram significativas, demonstrando que é possível a manipulação genética das características de plantas avaliadas de forma independente.

3. As regressões entre características avaliadas apresentaram baixos coeficientes de determinação, sugerindo que a maior parte da variação afetando uma característica não é dependente de outra.

4. É possível realizar seleção de plantas com características desejáveis para serem utilizadas em programas de melhoramento, sendo que as progênies da segunda família apresentaram, de forma geral, tipos superiores

\section{AGRADECIMENTOS}

Os autores agradecem ao Sr. Shu Otani, proprietário do pomar, pelo apoio financeiro do PRODETAB ao projeto e às agências CAPES, pela bolsa a J.D. e ao CNPq, pelas bolsas aos demais autores.

\section{REFERÊNCIAS}

ALLARD, R.W. Principles of plant breeding. 2. ed. New York: John Wiley \& Sons, 1999.253p.

BARNI, E.J.; DUCROQUET, J.P.; SILVA, M.C.; NETO, R.B.; PRESSER, R.F. Potencial de mercado para goiabeira-serrana catarinense. Florianópolis: Epagri, 2004. 48p. (Documento, 212)

CRAMER, C.S.; WEHNER, T. Fruit yield and yield component means and correlations of four slicing cucumber populations improved through six to tem cycles of recurrent selection. Journal of American Society of Horticultural Science, Alexandria, v.123, n.3, p.388-395, 1998.

DEGENHARDT, J.; ORTH, A.I.; GUERRA, M.P.; DUCROQUET, J.P.; NODARI, R.O. Morfologia floral da goiabeira serrana (Acca sellowiana) e suas implicações na polinização. Revista Brasileira de Fruticultura, Jaboticabal, v.23, n.3, p.718-721, 2001. (não consta no texto)

DEGENHARDT, J.; DUCROQUET, J.P.; REIS, M.S.; GUERRA, M.P.; NODARI, R.O. Efeito de anos e determinação do coeficiente de repetibilidade de características de frutos de goiabeira-serrana. Pesquisa Agropecuária Brasileira, Brasília, v.37, n.9, p.1285-1293, 2002. (não consta no texto)

DEGENHARDT, J.; DUCROQUET, J.P.; GUERRA, M.P.; NODARI, R.O Variação fenotípica de características de frutos em duas famílias de meios-irmãos de Goiabeira Serrana (Acca sellowiana Berg.) de um pomar comercial em São Joaquim, SC. Revista Brasileira de Fruticultura, Jaboticabal, v.25, n.3, p.475-479, 2003
DUCROQUET, J.P.H.J.; HICKEL, E.R. Fenologia da goiabeira serrana (Feijoa sellowiana Berg) no alto valo de Rio do Peixe, Santa Catarina. Revista Brasileira de Fruticultura, Cruz das Almas, v.13, n.3, p.313-320, 1991.

DUCROQUET, J.P.H.J.; HICKEL, E.R.; NODARI, R.O. Goiabeira serrana (Feijoa sellowiana). Jaboticabal: FUNEP, 2000, 66p. (Série Frutas Nativas, 5)

FALCONER, D.S. Introdução à genética quantitativa, Viçosa: UFV, 1987. $279 \mathrm{p}$.

GOMES, J.E.; PERECIN, D.; MARTINS, A.B.G.; ALMEIDA, E.J. Variabilidade fenotípica em genótipos de acerola. Pesquisa Agropecuária Brasileira, Brasília, v.35, n.11, p.2205-2211, 2000.

MANICA, I.; ICUMA, I.M.; JUNQUEIRA, N.T.V.; SALVADOR, J.O.; MOREIRA, A.; MALAVOLTA, E. Fruticultura tropical 6: goiaba. Porto Alegre: Cinco Continentes, 2000. 374p.

MATTOS, J.R. A goiabeira serrana. Porto Alegre; Instituto de Pesquisas de Recursos Naturais Renováveis, 1986. 84p. (Publicação IPRNR, 19)

NODARI, R.O; DUCROQUET, J.P.H.J.; GUERRA, M.P.; MELER, K. Genetic variability of Feijoa sellowiana germoplasm. Acta Horticulturae, Leuven, n.452, p.41-46, 1997.

PAIVA, J.R.; PAIVA, W.O.; CORDEIRO, E.R.; SABRY NETO, H. Parâmetros genéticos em progênies de polinização livre de acerola. Pesquisa Agropecuária Brasileira, Brasília, v.34, n.4, p.629-634, 1999.

PEREIRA, M.C.T.; SALOMÃO, L.C.C.; MOTA, W.F.; VIEIRA, G. Atributos físicos e químicos de frutos de oito clones de jabuticabeiras. Revista Brasileira de Fruticultura, Jaboticabal, v.22, n. Especial, p.16-21, 2000

SANTOS, C.A.F.; NASCIMENTO, C.E.S. Relação entre caracteres quantitativos do umbuzeiro (Spondias tuberosa A. CAMARA). Pesquisa Agropecuária Brasileira, Brasília, v.33, n.4, p.449-456, 1998

SANTOS, K.L.; FINARDI, C.; DUCROQUET, J.P.; NODARI, R.O. Caracterização genética dos acessos do banco de germoplasma de goiabeira-serrana (Acca sellowiana)" In: CONGRESSO BRASILEIRO DE FRUTICULTURA, 17., 2002, Belém-PA. Jaboticabal: SBF, 2002.p.1-5. 2002. CD-ROM

SOUZA, A.G.C.; SILVA S.E.L.; SOUSA, N.R. Avaliação de progênies de cupuaçuzeiro (Theobroma grandiflorum Willd. Ex Spreng. Schum) em Manaus - AM. Revista Brasileira de Fruticultura, Cruz das Almas, v.20, n.3, p.307-312, 1998.

STEEL, R.G.D.; TORRIE, J.H. Principles and procedures of statistics a biometrical approach. $2^{\text {nd }}$ ed. New York: McGraw-Hill Publishing, 1980.633p.

WELTER, L.J.; BELÓ, A.; DUCROQUET, J.P.; GUERRA, M.P.; NODARI, R.O. Genetic caracterization of the goiabeira-serrana (Feijoa sellowiana Berg) germplasm. In: Congresso Brasileiro de Genética, $45^{\circ}$, Gramado (RS), Anais..., Revista Brasileira de Genética, Ribeirão Preto, v.22, n.3, suppl., p.301, 1999. 